\title{
The difficult airway in the emergency department
}

\author{
Evelyn Wong • Yih-Yng Ng
}

Received: 29 January 2008 / Accepted: 29 April 2008 / Published online: 29 May 2008

(C) Springer-Verlag London Ltd 2008

\begin{abstract}
Background The patient with difficult airways is a common challenge for emergency physicians.

Aims Our goal was to study the reasons for difficult airways in the emergency department.

Methods We performed a prospective observational study of patients requiring advanced airway management from 1 January 2000 to 31 December 2006.

Results There were 2,343 patients who received advanced airway management of which $93(4.0 \%)$ were deemed difficult. The main diagnoses were cardiac arrest (28), trauma (27) and congestive heart failure (10). The main reasons for the difficult airways were attributed to an anterior larynx $(38,40.9 \%)$, neck immobility $(22,23.7 \%)$ as well as the presence of secretions and blood (14, 15.1\%). The mean number of attempts at intubation was 3.6 versus 1.2 for all cases. The mortality rate of $40.5 \%$ among patients with difficult airways was not different from that of all patients who had airway management $(41 \%)$. There were seven $(0.3 \%)$ failed airways. Anaesthetists performed $21(22.6 \%)$ of the rescue airways while surgeons performed $5(5.4 \%)$. Of the rescue strategies performed, 24 were through the use of the bougie, 3 by cricothyroidotomy, 4 by tracheostomy, 6 with the GlideScope and 3 with the laryngeal mask airway. The rest the airways were secured by tracheal intubation using the laryngoscope.
\end{abstract}

Disclaimer: The views expressed in this paper are those of the author(s) and not those of the editors, editorial board or publisher.

E. Wong $(\bowtie) \cdot$ Y.-Y. Ng

Department of Emergency Medicine, Singapore General Hospital,

Outram Road,

Singapore 169608, Singapore

e-mail: evelyn.wong@sgh.com.sg
Conclusions Emergency physicians manage most of the difficult airways successfully (68.8\%). However, the success rate can be further improved through the more frequent use of the bougie or other rescue device. A possible suggestion would be for the emergency physician to use the bougie after the second or third attempt at direct orotracheal intubation.

Keywords Airway · Intubation · Laryngoscopy · Cricothyroidotomy Tracheostomy

\section{Introduction}

The difficult airway is a challenge to emergency physicians. In the anaesthesia literature, is frequency ranges from 0.4 to $8.5 \%[1-3]$ of elective intubations. In the emergency medicine literature, is more common-from 2 to $14.8 \%$ [4-9] - but it includes prehospital intubation and may be performed by paramedics or doctors.

The definition of the difficult airway varies in different literature sources. The American Society of Anesthesiologists Task Force on Management of the Difficult Airway defines it as the clinical situation in which a conventionally trained anaesthesiologist experiences difficulty with face mask ventilation of the upper airway, difficulty with tracheal intubation or both [10]. Suggested descriptions of the difficult airway include but are not limited to difficult face mask ventilation, difficult laryngoscopy, difficult tracheal intubation and failed intubation. The emergency medicine literature generally considers the difficult airway in three dimensions: difficult mask ventilation, difficult intubation and difficult cricothyroidotomy, by experienced personnel [11]. There is no consistent or single definition of the difficult and the failed airway. 
Table 1 Primary diagnoses

\begin{tabular}{llll}
\hline Diagnoses & Difficult cases & Total & \% Total \\
\hline Seizure & 4 & 24 & 16.7 \\
Burns & 5 & 34 & 14.7 \\
Pneumonia & 8 & 65 & 12.3 \\
Trauma & 22 & 310 & 7.1 \\
CVA & 5 & 158 & 3.2 \\
Cardiac arrest & 28 & 917 & 3.1 \\
Other & 8 & 275 & 2.9 \\
Acute pulmonary oedema & 10 & 422 & 2.4 \\
Asthma & 3 & 138 & 2.2 \\
Total & 93 & 2343 & 4.0 \\
\hline
\end{tabular}

CVA cerebrovascular accident

This paper aims to identify the reasons for difficult airways in emergency medicine practice as well as to study the rescue methods used in a tertiary hospital in South-East Asia.

\section{Methods}

The study site emergency department has an ongoing airway registry that prospectively captures patient demographics, diagnosis, indications for intubation, persons and discipline of intubating physicians, number of attempts, method of intubation including rescue methods, reasons for difficult intubation, success rates and complications. Data are collected using a study form, which is completed by the intubating physician immediately after the procedure. Where the data were incomplete, the research assistant would approach the intubating physician to fill the gaps. This project was approved by the hospital's Ethics Committee.

The data used for this study were from 1 January 2000 to 31 December 2006. The data were analysed using the Statistical Package for the Social Sciences (SPSS) software for Windows (version 10.1; SPSS Inc).

Table 2 Reasons for difficult intubation

\begin{tabular}{lll}
\hline Reasons for difficulty & No. & $\%$ \\
\hline Anterior larynx & 38 & 40.9 \\
Neck immobility & 22 & 23.7 \\
Secretions and blood & 14 & 15.1 \\
Small mouth $<3$ fingerbreadths & 13 & 14.0 \\
Obesity & 10 & 10.8 \\
Incomplete frontal dentition & 8 & 8.6 \\
Airway oedema & 8 & 8.6 \\
Oral obstruction (tumour, mechanical obstruction) & 7 & 7.5 \\
Maxillofacial trauma & 4 & 4.3 \\
Combativeness & 2 & 2.2 \\
\hline
\end{tabular}

Table 3 Personnel performing the first intubation and rescue attempts

\begin{tabular}{lll}
\hline Personnel & First & Rescue \\
\hline Emergency physician & $85(91.3 \%)$ & $64(68.8 \%)$ \\
Anaesthetist & $2(2.2 \%)$ & $21(22.6 \%)$ \\
Surgeon & $2(2.2 \%)$ & $5(5.4 \%)$ \\
Critical care & $4(4.3 \%)$ & $3(3.2 \%)$ \\
Total & $93(100 \%)$ & $93(100 \%)$ \\
\hline
\end{tabular}

Definitions

For the purpose of this study, we adopted the following definitions:

1. A difficult airway is one where there was difficulty administering adequate mask ventilation or if there were at least three attempts at orotracheal intubation or a failed intubation or if cricothyroidotomy was difficult.

2. A failed airway is one where tracheal intubation cannot be achieved, after multiple attempts, by the orotracheal or nasal-tracheal or transtracheal (cricothyroidotomy or tracheostomy) route or attempts at intubation are abandoned.

\section{Results}

From 2000 to 2006, there were a total of 808,721 emergency department (ED) visits; 2,343 of them required advanced airway intervention, giving a rate of 2.9 per 1,000 emergency department visits. Ninety-three $(4.0 \%)$ of these were deemed difficult intubations, seven $(0.3 \%)$ of which were failed airways. The mean age of the patients was 57 years for patients with difficult intubations compared to 63 years for all patients in the registry. The gender ratio was $75.5 \%$ men in the difficult airway group compared to $66.5 \%$ men among all patients.

The most common indications for intubation were cardiac arrest $(39.1 \%)$, acute pulmonary oedema (18.0\%) and trauma (13.2\%). However, the most common diagnoses resulting in difficult intubations were seizure (16.7\%), burns (14.7\%) and pneumonia (12.3\%) (Table 1).

Table 4 Methods of intubation for the first and final attempts

\begin{tabular}{lll}
\hline Method & First attempt & Final attempt \\
\hline OTI, no medications & 46 & 43 \\
OTI, induction & 11 & 9 \\
RSI & 35 & 34 \\
Cricothyroidotomy & 1 & 3 \\
Tracheostomy & 0 & 4 \\
\hline
\end{tabular}

OTI orotracheal intubation, RSI rapid sequence intubation 
Table 5 Rescue devices

\begin{tabular}{lll}
\hline Rescue device & No. & $\%$ \\
\hline Laryngoscope, curved blade & 51 & 54.8 \\
Laryngoscope, curved blade and bougie & 24 & 25.8 \\
GlideScope & 6 & 6.5 \\
Formal tracheostomy & 4 & 4.3 \\
LMA & 3 & 3.2 \\
Cricothyroidotomy & 3 & 3.2 \\
Laryngoscope, straight blade & 2 & 2.2 \\
\hline
\end{tabular}

LMA laryngeal mask airway

The three most common reasons cited for difficult intubations were the presence of an anterior larynx (40.9\%), neck immobility (23.7\%) and profuse oral secretions and bleeding (15.1\%) (Table 2). The Mallampati score was seldom used.

The mean number of attempts at intubation was 3.6 for the difficult airway group and 1.2 for all patients in the registry.

Emergency physicians were most likely to attempt difficult intubations first $(91.3 \%)$ and were most likely to also perform the rescue attempt $(68.8 \%)$. Anaesthetists performed $22.6 \%$ of rescue airways (Table 3 ).

Of the 46 patients who underwent orotracheal intubation with no drugs, 3 were converted to surgical airways (2 cricothyroidotomies and 1 tracheostomy). Of the 11 patients who underwent orotracheal intubation with induction agents only 2 had to receive neuromuscular blocking agents subsequently through rapid sequence intubation (RSI). Three of the patients who initially had RSI subsequently had tracheostomies performed by the surgeons (Table 4).

The most common rescue device used in our department was the Macintosh-type laryngoscope with the curved blade alone $(54.8 \%)$, followed by the laryngoscope with the bougie $(25.8 \%)$ and the GlideScope (6.5\%) (Table 5). Most of the bougie attempts were made by anaesthetists $(83.3 \%)$.

There were seven failed airways but no deaths attributed to the failures (Table 6). The mortality rate of $40.5 \%$ among patients with difficult airways was not different from that of all patients who had airway management $(41.0 \%)$. There were four cricothyroidotomies and four tracheostomies. The surgical airway rate was $0.3 \%$. Three of the cricothyroidotomies were performed by emergency physicians while the rest of the surgical airways were performed by surgeons. There was one failed cricothyroidotomy in a female patient with previous radiation therapy to the head and neck. Her airway was subsequently secured with orotracheal intubation with a bougie by an anaesthetist. She had a Cormack-Lehane grade 3 larynx. There was no "unable to ventilate-unable to intubate" situation.

\section{Discussion}

The difficult airway is a challenge to both the emergency physician and the anaesthetist. Its incidence in the ED is understandably higher as there is a disproportionately larger number of patients requiring airway management as a result of acute medical or surgical conditions which by themselves contribute to the difficulty. Examples of these would be maxillofacial trauma, respiratory burns and the various causes of laryngeal oedema. Airway management in the ED often occurs in an unpredictable and uncontrolled environment, sometimes with the patient arriving unannounced. The unique situation of having a high proportion of difficult airways and an unpredictable environment affords the emergency physician the opportunity to become an expert in emergency and difficult airway management.

The difficult airway might be considered in three areas: difficult bag-mask ventilation, difficult intubation and difficult surgical airway. The difficult bag-mask ventilation scenario would generally preclude paralysis with neuromuscular blocking agents but it does not imply difficulty in intubation. Reasons for difficult ventilation include difficult mask fit, obesity, obstruction, age over 65, "no teeth" and
Table 6 Failed emergency department airways

$E M$ emergency medicine, $A N$ anaesthesia, $G S$ general surgery, $O T$ operating theatre

\begin{tabular}{|c|c|c|c|c|c|}
\hline $\begin{array}{l}\text { Case } \\
\text { no. }\end{array}$ & Diagnosis & $\begin{array}{l}\text { No. } \\
\text { attempts }\end{array}$ & Personnel & Reasons & Outcome \\
\hline 1 & $\begin{array}{l}\text { Chronic renal failure with } \\
\text { acute pulmonary oedema }\end{array}$ & 3 & EM, AN & $\begin{array}{l}\text { Obesity, small mouth, } \\
\text { anterior larynx }\end{array}$ & $\begin{array}{c}\text { Admitted, } \\
\text { dialysis }\end{array}$ \\
\hline 2 & Cardiac arrest & 1 & EM & Small mouth & Died \\
\hline 3 & Cardiac arrest & 6 & $\mathrm{EM}, \mathrm{AN}$ & $\begin{array}{l}\text { Neck scarring, } \\
\text { oedematous airway, } \\
\text { secretions }\end{array}$ & Died \\
\hline 4 & Pneumonia & 6 & $\begin{array}{l}\text { EM, AN, } \\
\text { GS }\end{array}$ & Subglottic stenosis & $\begin{array}{l}\text { Tracheostomy } \\
\text { in OT }\end{array}$ \\
\hline 5 & Cardiac arrest & 6 & $\mathrm{EM}, \mathrm{AN}$ & Anterior larynx, grade 4 & Died \\
\hline 6 & Cardiac arrest & 1 & EM & Small mouth, rigor & Died \\
\hline 7 & Cardiac arrest & 3 & EM & Anterior larynx & Died \\
\hline
\end{tabular}


"stiff lungs". This difficulty is generally not measured, but rather, it is the "unable to ventilate and unable to intubate" scenario that is considered the true difficulty. We did not encounter this in our study. This is not unexpected as its incidence rate is often quoted to be low and is rarely quantified $[9,12,13]$. There is a role for the use of supraglottic devices, e.g. the laryngeal mask airway (LMA) or Combitube or laryngeal tube, in some of these cases especially in the obese, elderly and edentulous and for those with difficult mask fit [14].

Our difficult intubation rate was $4 \%$ while our failed intubation rate was $0.7 \%$. This compares with $2.7-12.3 \%$ cited in the emergency medicine literature [5-9, 15] and $0.13-4 \%$ in the anaesthesia literature [1-3]. Among the 93 difficult intubations, $78(83.9 \%)$ were due to an anterior larynx, neck immobility, obesity and incomplete frontal dentition. Video laryngoscopy shows promise in overcoming these difficulties. Our department acquired the GlideScope ${ }^{\circledR}$ in November 2005. However, there was a learning phase and the results in 2006 did not reflect a downward trend in the incidence of difficult airway. It would be interesting to study the effect of video laryngoscopy on difficult airways and whether the incidence falls with its use. This would entail prolonging the duration of our study beyond the duration of the learning phase.

Our surgical airway rate was $0.3 \%$, half of which were cricothyroidotomies and half were tracheostomies. Our surgeons generally prefer to perform tracheostomies when called to secure the difficult airway. The cricothyroidotomy rate among other ED are between 0.6 and $0.9 \%[4,15,16$, 21-23]. We had one failed cricothyroidotomy. The causes of difficult cricothyroidotomy include anterior neck swellings, infections, obesity, post-radiation therapy as well as main stem bronchial and tracheal injuries. The incidence of difficult surgical airways is unknown.

While the recognition of a difficult airway is important, the authors believe that the value of skills acquisition, wellprepared airway strategies and equipment innovation cannot be overemphasized. Various studies [15-21] have shown that experience and the use of modern airway equipment do improve intubation success rates; however, it would be difficult to study the effect of having planned strategies or algorithms in airway management.

\section{Limitations}

Although this was a prospective observational study, there were several limitations. Incomplete documentation was the most common problem and was present in $16 \%$ of our study forms. There was also a possibility of underdeclaration of the number of attempts at intubation or any complications or adverse events. The research assistant however did attempt to clarify any ambiguity with the primary intubators retrospectively in order to get as accurate a documentation as possible. This was done within 1 week of the intubation. There was also the possibility of incomplete capture of all intubations performed in the department. The researchers tried to minimize this by counterchecking with the trauma registry and mortality records every week.

With regard to attempting to qualify why certain intubations were difficult, physicians would often label an airway as "anterior" rather than to document whether the thyromental or thyrohyoid distance was small. Future studies should be designed to have more specific data fields on the various components contributing to the difficult airway. In addition, with the advancement of medical technology, it would be interesting to study if the number of attempts at intubation and the difficult and failed airway rates would decline.

\section{Conclusions}

Emergency physicians manage most difficult airways $(68.8 \%)$ successfully. The success rate by the emergency physicians can be further improved through the more frequent use of the bougie or other rescue device like video laryngoscopy. A possible suggestion would be for the emergency physician to use the bougie after the second or third attempt at direct orotracheal intubation.

Acknowledgements We would like to thank Ms. Seow Gek Ching for her work with the database, Mr. Koh Seoh Kwee for providing the departmental statistics and all doctors and nurses who contributed to the study.

\section{References}

1. Burkle CM, Walsh MT, Harrison BA, Curry TB, Rose SH (2005) Airway management after failure to intubate by direct laryngoscopy: outcomes in a large teaching hospital. Can J Anaesth 52:634-640

2. Samsoon GLT, Young JRB (1987) Difficult tracheal intubation: a retrospective study. Anaesthesia 42:487-490

3. Crosby ET, Cooper RM, Douglas MJ, Doyle DJ, Hung OR, Labrecque $P$ et al (1998) The unanticipated difficult airway with recommendations for management. Can J Anaesth 45(8):757776

4. Sagarin MJ, Barton ED, Chng YM, Walls RM (2005) Airway management by US and Canadian emergency medicine residents: a multicenter analysis of more than 6,000 endotracheal intubation attempts. Ann Emerg Med 46(4):328-336

5. Timmermann A, Eich C, Russo SG, Natge U, Brauer A, Rosenblatt WH, Braun U (2006) Prehospital airway management: a prospective evaluation of anaesthesia trained emergency physicians. Resuscitation 70:179-185 
6. Jacobs LM, Berrizbeitia LD, Bennett B, Madigan C (1983) Endotracheal intubation in the prehospital phase of emergency medical care. JAMA 250:2175-2177

7. Adnet F, Jouriles NJ, Le Toumelin P et al (1998) A survey of outof-hospital emergency intubations in the French prehospital medical system: a multicenter study. Ann Emerg Med 32:454-460

8. Cantineau JP, Tazarourte K, Merckx P et al (1997) Tracheal intubation in prehospital resuscitation: importance of rapidsequence induction anesthesia (in French). Ann Fr Anesth Reanim $16: 878-884$

9. Kovacs G, Law JA, Ross J, Tallon J, MacQuarrie K, Petrie D, Campbell S, Soder C (2004) Acute airway management in the emergency department by non-anesthesiologists. Can J Anaesth 51(2):174-180

10. American Society of Anesthesiologists Task Force on Management of the Difficult Airway (2003) Practice guidelines for management of the difficult airway: an updated report by the American Society of Anesthesiologists Task Force on Management of the Difficult Airway. Anesthesiology 98(5):12691277

11. Murphy MF, Walls RM (2000) The difficult and failed airway. In: Walls RM, Luten RC, Murphy MF, Schneider RE (eds) Manual of emergency airway management. Lippincott Williams \& Wilkins, Philadelphia

12. Walsh K, Cummins F, Keogh J et al (2000) Effectiveness of mask ventilation performed by hospital doctors in an Irish tertiary referral teaching hospital. Ir Med J 93:55-57

13. Wang HE, Kupas DF, Paris PM, Bates RR, Yealy DM (2003) Preliminary experience with a prospective, multi-centered evaluation of out-of-hospital endotracheal intubation. Resuscitation 58:49-58

14. Kurola J, Turunen MJ, Kettunen T, Laakso JP, Gorski J, Paakkonen H, Silfvast T (2005) A comparison of the laryngeal tube and bag-valve mask ventilation by emergency medical technicians: a feasibility study in anesthetized patients. Anesth Analg 101:1477-1481

15. Bair AE, Filbin MR, Kulkarni RG, Walls RM (2002) The failed intubation attempt in the emergency department: analysis of prevalence, rescue techniques, and personnel. J Emerg Med 23 (2):131-140

16. Jabre P, Combes X, Leroux B et al (2005) Use of gum elastic bougie for prehospital difficult intubation. Am J Emerg Med 23:552-555

17. Tentillier E, Heydenreich C, Cros AMet al (2008) Use of the intubating laryngeal mask airway in emergency pre-hospital difficult intubation. Resuscitation 77(1):30-34. DOI 10.1016/j. resuscitation.2007.06.035

18. Kurola J, Harve H, Kettunen T, Laakso JP, Gorski J, Paakkonen H, Silfvast T (2004) Airway management in cardiac arrest-comparison of the laryngeal tube, tracheal intubation and bag-valve mask ventilation in emergency medical training. Resuscitation 61:149-153

19. Wang HE, Sweeney TA, O'Conner RE, Rubinstein H (2001) Failed prehospital intubations: an analysis of emergency department courses and outcomes. Prehosp Emerg Care 5(2):134-141

20. Crosby E (2002) Modelling the difficult airway-how real is faking it? Can J Anaesth 49(5):448-452, comment on Can J Anaesth (2002) 49:525-526

21. Herff H, Wenzel V, Dorges V (2008) Avoiding field airway management problems. Resuscitation 77:4-5. DOI 10.1016/j. resuscitation.2007.11.004

22. Combes X, Jabre P, Jbeili C, Laroux B, Bastuji-Garin S, Margenet A, Adnet F, Dhonneur G (2006) Prehospital standardization of medical airway management: incidence and risk factors of difficult airway. Acad Emerg Med 13:828-34

23. Wang HE, Kupas DF, Paris PM, Bates RR, Constantino JP, Yealy DM (2003) Multivariate predictors of failed prehospital endotracheal intubation. Acad Emerg Med 10(7):717-724 